\title{
Clavicle Fractures: Allman and Neer Classification
}

\author{
Holder J*, Kolla S and Lehto S
}

Department of Radiology, SUNY Downstate Medical Center, Brooklyn, NY, USA

${ }^{*}$ Corresponding author: Holder J, MD., Resident Physician, Department of Radiology, SUNY Downstate Medical Center, 450 Clarkson Avenue, Brooklyn, NY, USA 11203, Fax: 718-270-2667, Tel: 917-626-9453, E-mail: Justin.holder@downstate.edu

Citation: Holder J, Kolla S, Lehto S (2017) Clavicle Fractures: Allman and Neer Classification. J Adv Radiol Med Image 2(1): 102. doi: 10.15744/2456-5504.2.102

Received Date: September 30, 2016 Accepted Date: January 12, 2017 Published Date: January 13, 2017

\begin{abstract}
Clavicle fractures are common injuries in young adults and children, and diagnosis can often be made based on history and physical exam. Treatment decisions vary according to the fracture's location and multiple classification schemes have been devised to describe fracture patterns. The Allman model is the most widely used, which Dr. Neer subsequently revised to further delineate distal clavicle patterns. This article will illustrate the anatomy of the clavicle, its attachments and clinically relevant injury patterns. It is imperative to accurately classify these injuries as clinical outcomes and management options vary according to their morphology.
\end{abstract}

Keywords: Clavicle; Allman; Neer

List of Abbreviations: SSSC: Superior Suspensory Complex; CCL: Coracoclavicular Ligament

\section{Introduction}

Trauma to the shoulder is common and imaging identifies factors that require emergent interventions. Many injuries disrupt normal anatomy to predispose the patient to functional impairment and delayed complications. Comprehending injury patterns and associated injury mechanisms facilitates accurate diagnosis and expedites therapeutic interventions. Imaging thus plays an essential role in the diagnostic work up and management of these patients.

$2-5 \%$ of all adult fractures and $10-15 \%$ of all childhood fractures involve the clavicle. There is a bimodal age distribution, with young males less than 30 years old and elderly patients over 70 years old being the most commonly afflicted population groups. Approximately two-thirds of fractures involve the mid-diaphysis in adults, whereas up to $90 \%$ of injuries involve the diaphysis in children [1].

Management decisions often depend on fracture location, and multiple classification systems have been designed to describe fracture patterns. The Allman and Neer categorizations will be presented, and demonstrations of the various fracture types will be correlated with imaging demonstrations. An algorithmic approach will then be devised to accurately classify clavicle fractures.

\section{Discussion}

\section{Anatomy}

The clavicle is the primary support structure between the scapula and sternum, which articulates with the sternal manubrium medially and with the acromion of the scapula laterally (Figure 1). The trapezius, sternocleidomastoid, sternohyoid and deltoid muscles also attach to the clavicle (Figure 2 and 3). The clavicle thus provides significant stability and power to the arm and shoulder [2].

The sternoclavicular joint connects the axial skeleton to the upper limb and is composed of the superior manubrium, the medial end of the clavicle, anterosuperior and posterior thickening of the joint capsule (which form capsular ligaments), interclavicular and costoclavicular (rhomboid) ligaments (Figure 4) [3]. The costoclavicular ligament originates from the first rib and attaches to the undersurface of the medial clavicle at its costal tuberosity, and this insertion is often mistaken for medial clavicle fractures (Figure 5) [4].

The coracoclavicular ligament is a vertical stabilizing structure for the acromioclavicular joint and plays an integral part in clavicle fracture classification. It consists of tow parts: the conoid and trapezoid ligaments. The conoid is more medial, originates from 
the coracoid process of the scapula and inserts onto the conoid process on the undersurface of the clavicle. The trapezoid is more lateral, originates more anteriorly on the coracoid process and inserts on the trapezoid line on the undersurface of the clavicle (Figure 6) $[5,6]$.

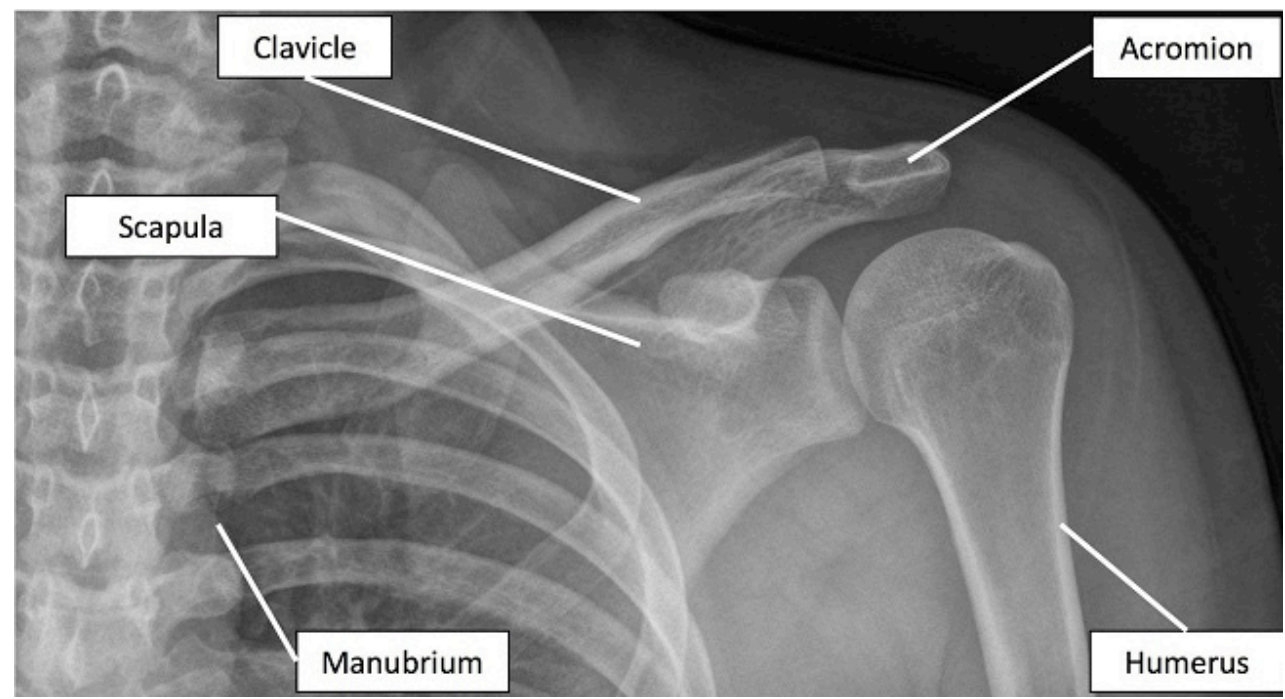

Figure 1: Frontal radiograph demonstrates normal anatomy of the clavicle and its articulations

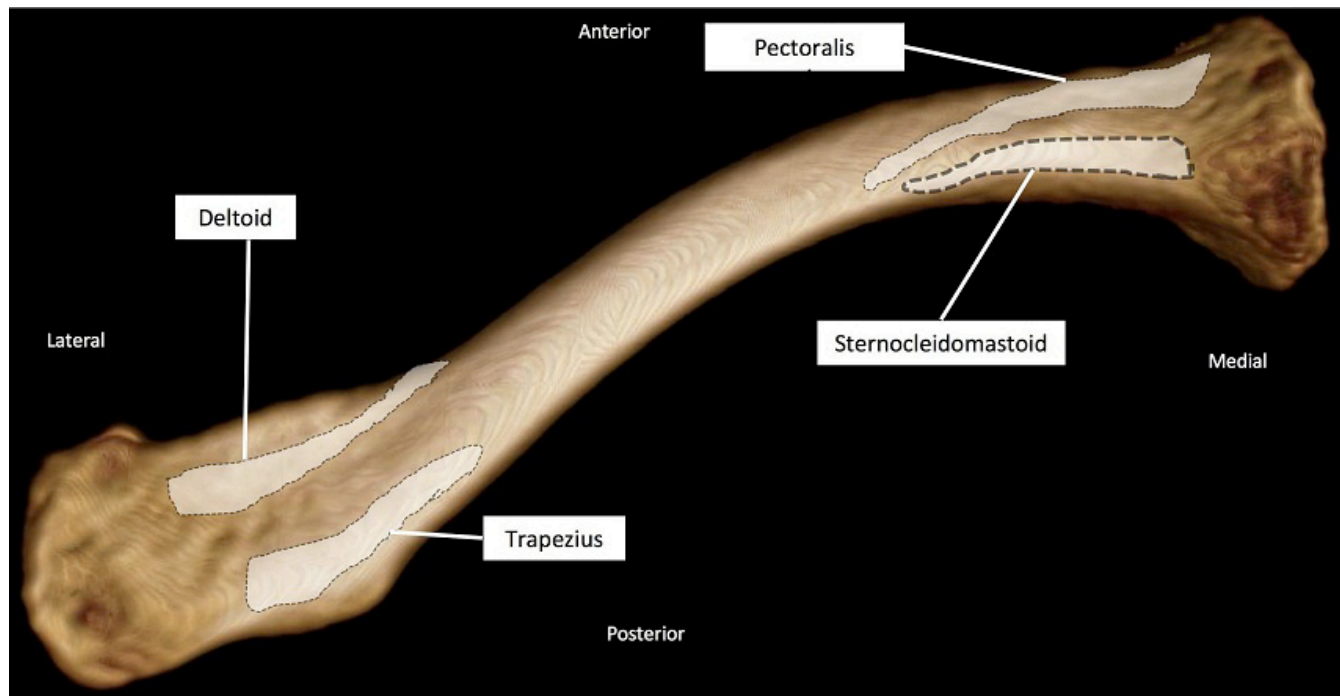

Figure 2: Three dimensional (3D) computed tomography (CT) model of superior surface of clavicle demonstrates muscular attachments

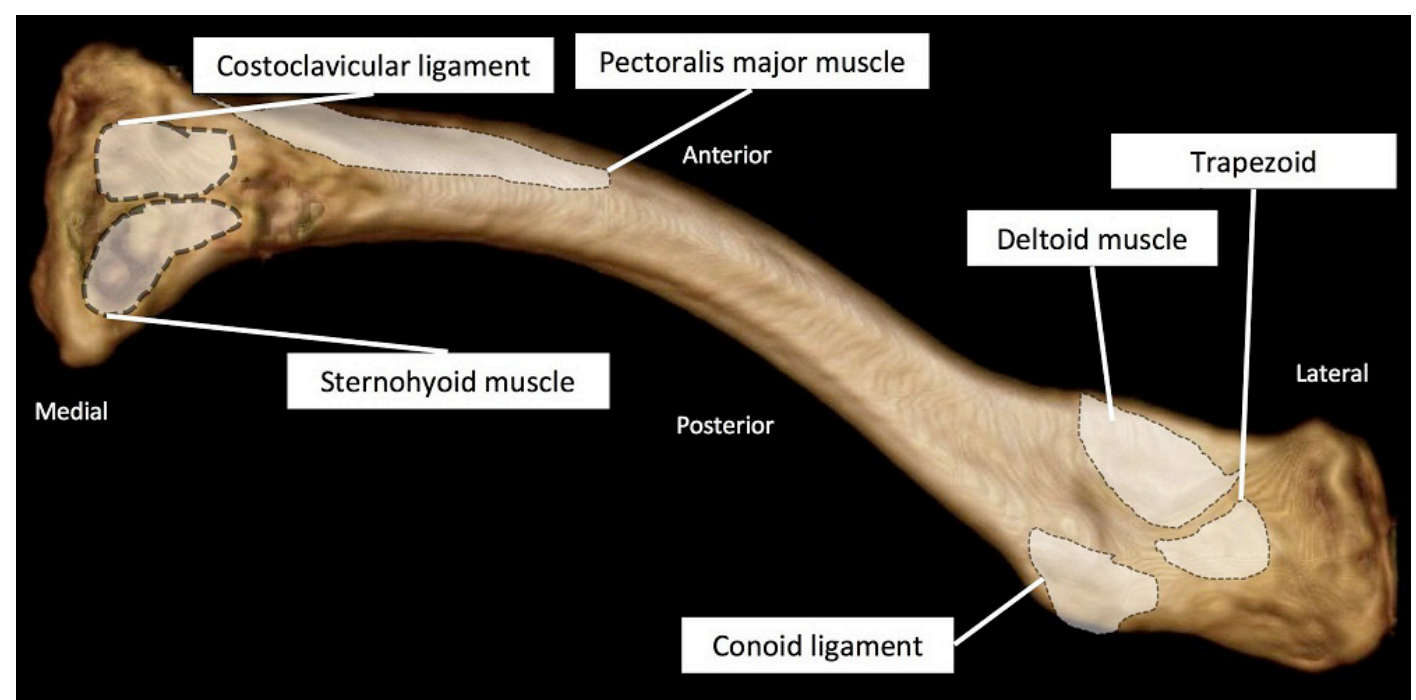

Figure 3: 3D CT model of inferior surface clavicle demonstrates muscular and ligamentous attachments 


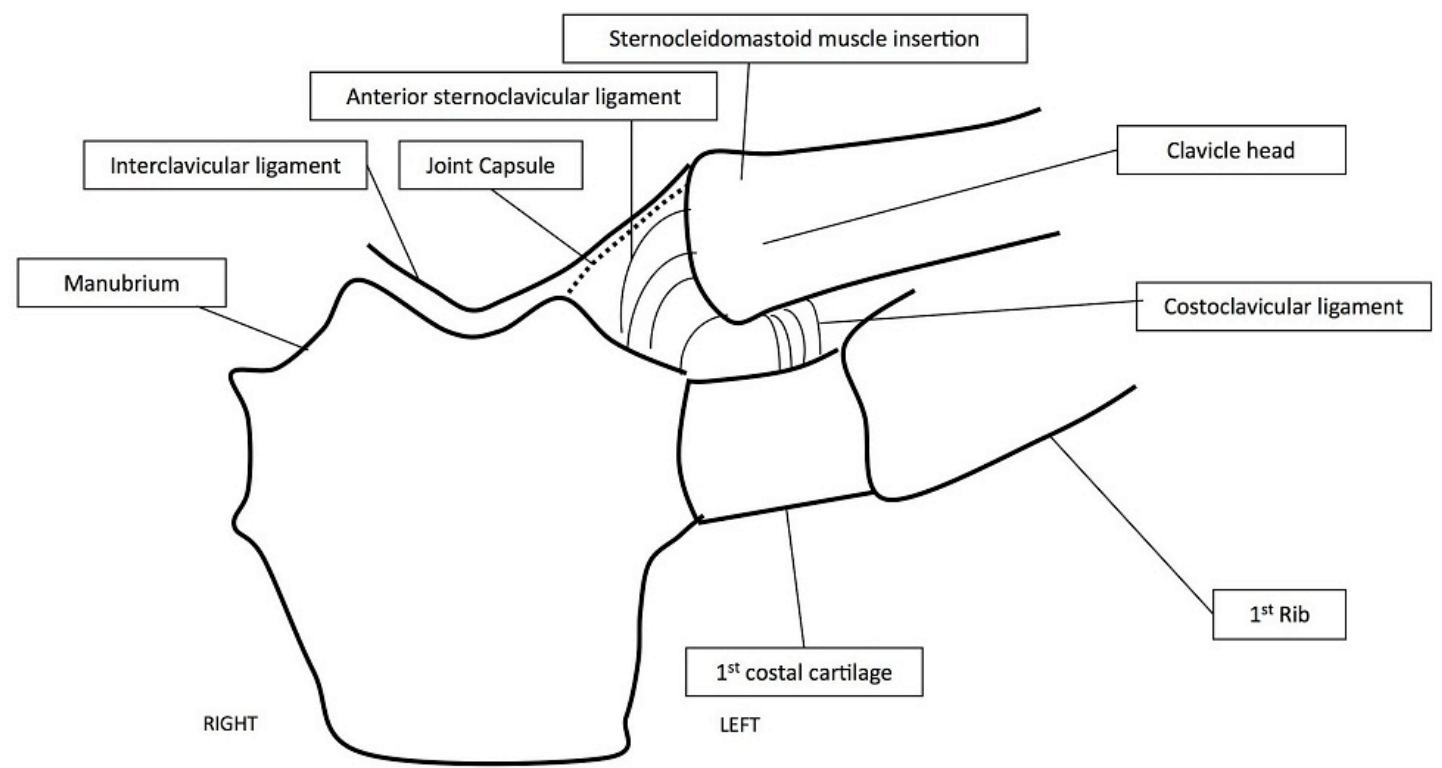

Figure 4: Illustration of the sternoclavicular joint anatomy

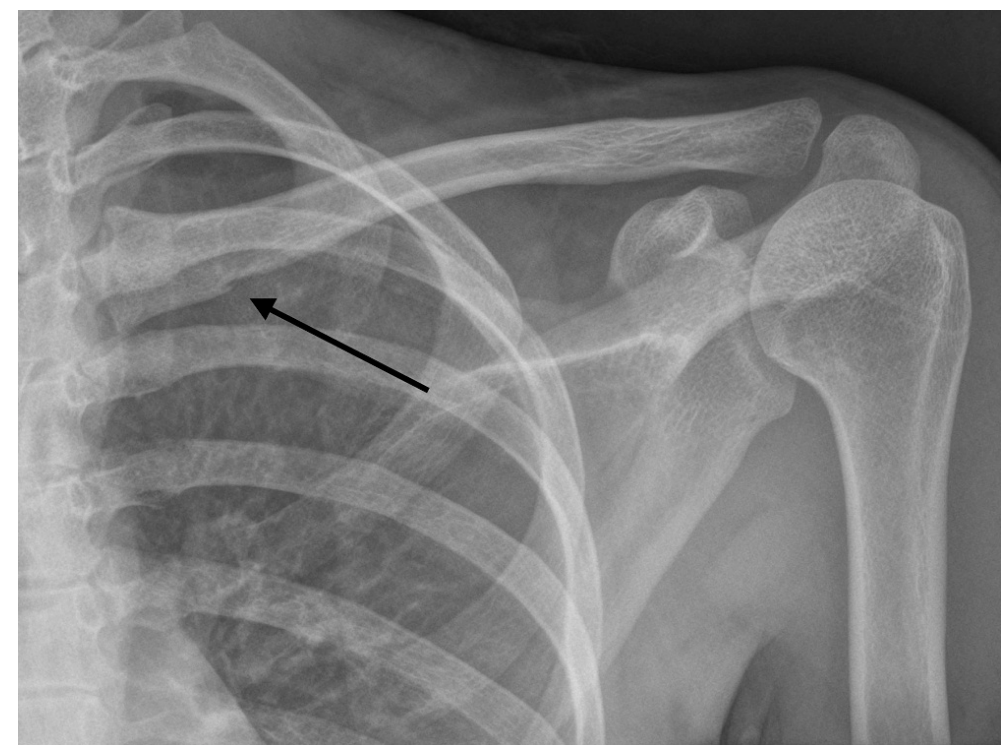

Figure 5: Frontal radiograph of the medial clavicle demonstrates focal osseous protuberance (arrow), representing insertion of rhomboid ligament, which may mimic fractures

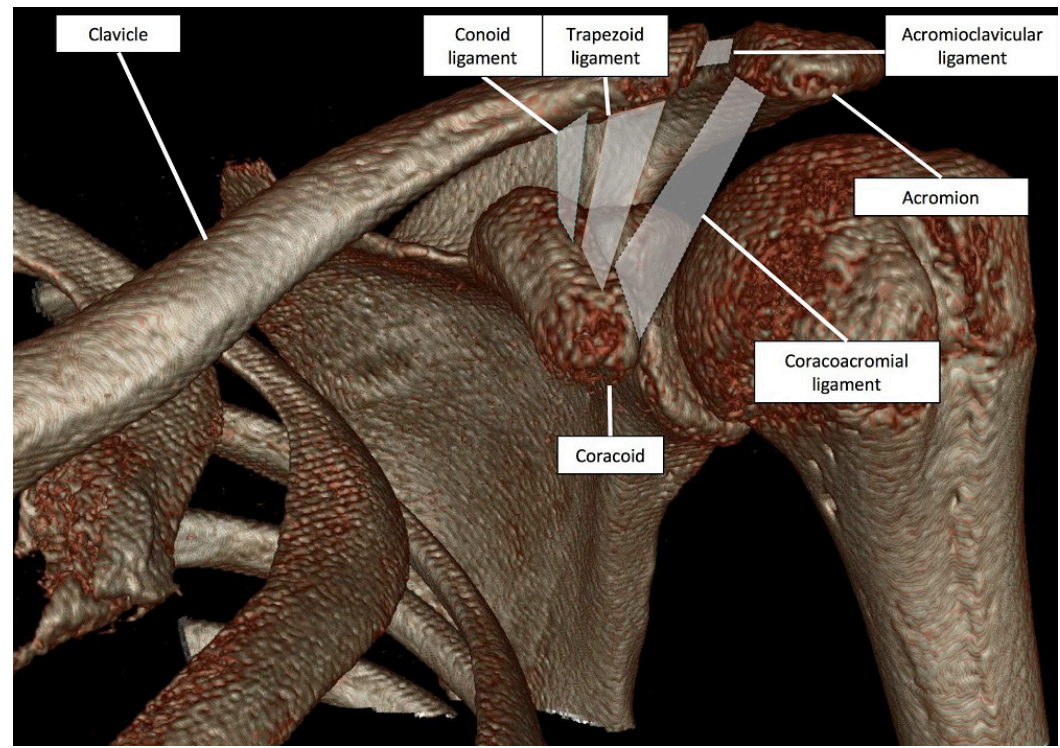

Figure 6: 3D CT model of the distal clavicle, scapula and proximal humerus demonstrates ligamentous attachments of the distal clavicle 
The clavicle, scapula and multiple ligaments comprise the shoulder girdle. The shoulder girdle interacts with the glenohumeral articulation to form the shoulder. The superior suspensory complex (SSSC) is a complex of multiple structures that form an osseous and soft tissue ring from which the upper extremity is suspended [7]. The clavicle and the lateral scapula (including the acromion and coracoid processes), as well as acromioclavicular, coracoclavicular, and coracoacromial ligaments comprise the SSSC (Figure 7) [8]. The middle third of the clavicle and scapular body/glenoid neck junction form the superior and inferior struts, respectively, of the SSC and attach this complex to the trunk to provide the shoulder girdle's major stabilizing force [7].

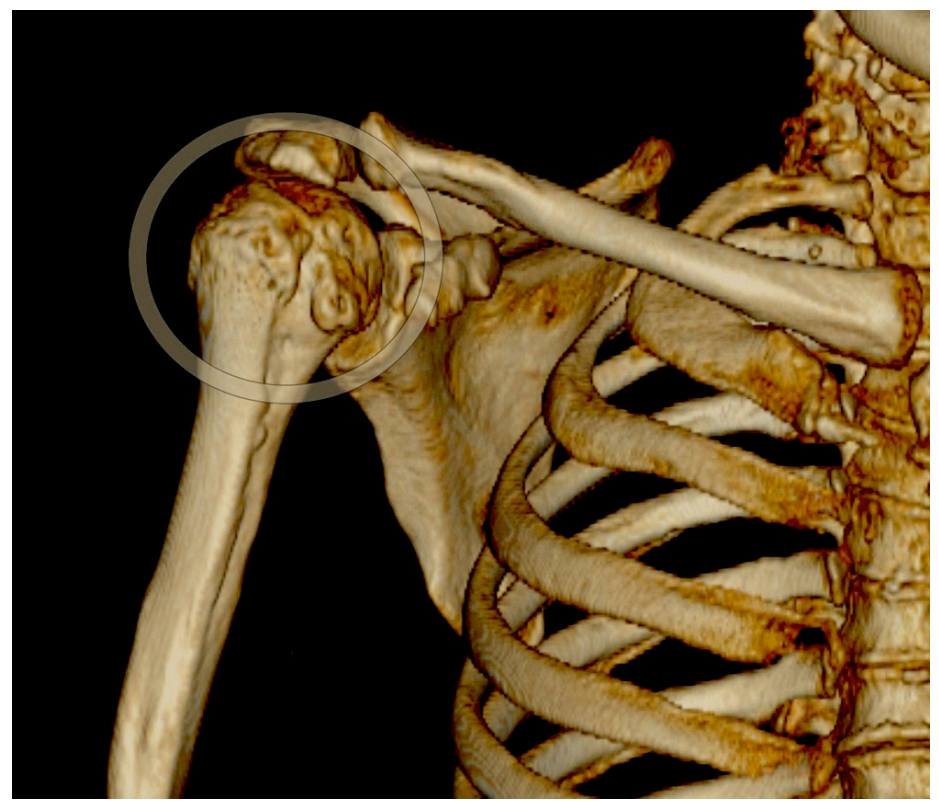

Figure 7: 3D CT model of the shoulder illustrates the superior suspensory complex

When a single portion of the SSSC is disrupted there is minimal to no functional deficit, and the patient is often treated conservatively. Injuries to two or more structures cause varying degrees of instability, however, and often necessitate surgical treatment. Disruptions can occur as two ligamentous injuries, two fractures or a combination of both. Instability most commonly occurs from fractures of the distal clavicle and acromioclavicular or coracoclavicular ligaments, the scapular neck and lateral body, the coracoid and acromion process, or the [2].

\section{Mechanism of Injury}

$35-45 \%$ of fractures affecting the shoulder girdle involve the clavicle and these injuries are most commonly caused by lateral direct impaction, wherein the compressive force acts along the clavicle shaft. This often occurs when patients fall onto their shoulder with the arm in adduction. Indirect mechanisms of injury include rotational, translational or axial momentum of the body around the shoulder (often occurring during a fall on an outstretched hand), as well as muscular contractions around the shoulder [2].

\section{Imaging}

Plain films are often the first and only imaging modality used to characterize clavicle fractures. Apical oblique views with up to $45^{\circ}$ cephalic tilt and frontal views are often sufficient to characterize fractures. The degree of combination and displacement, as well as fracture location should be described [2].

\section{Classification}

Dr. Allman first described his classification system in 1967, which divides the clavicle into thirds and lists fractures in descending order of incidence [1].

Fractures involving middle third of the clavicle are classified as Group 1. These are the most commonly encountered types, accounting for approximately $80 \%$ of injuries (Figure 8 and 9) [2].

Fractures that involve the portion of the clavicle lateral to the CCL correspond to Group II fractures [2]. Dr. Neer further divided these into subtypes that factor in the acromioclavicular joint integrity and CCL attachments [9]. Type 1 fractures occur in between the conoid and trapezoid ligaments of the CCL, and remain attached to the medial and lateral fragments, respectively. There is usually minimal to no displacement (Figure 10 and 11). Type 2 fractures are medial to the CCL attachment, and this medial fragment separates from the CCL. This type is further divided into the subtypes $2 \mathrm{~A}$ and $2 \mathrm{~B}$. The conoid and trapezoid ligaments remain attached to the distal fragment in type $2 \mathrm{~A}$ (Figure 12 and 13), while the conoid is detached from the proximal fragment and the trapezoid remains attached to the distal fragment in type 2B (Figure 14 and 15). Type 3 involves intra-articular extension (Figure 16 and 17). Type 4 is a periosteal sleeve avulsion from the inferior cortex while attached to the coracoclavicular ligament, 
wherein the medial fragment is often displaced superiorly (Figure 18 and 19). Type 5 also involves an avulsion of the CCL (Figure 20 and 21) [10].

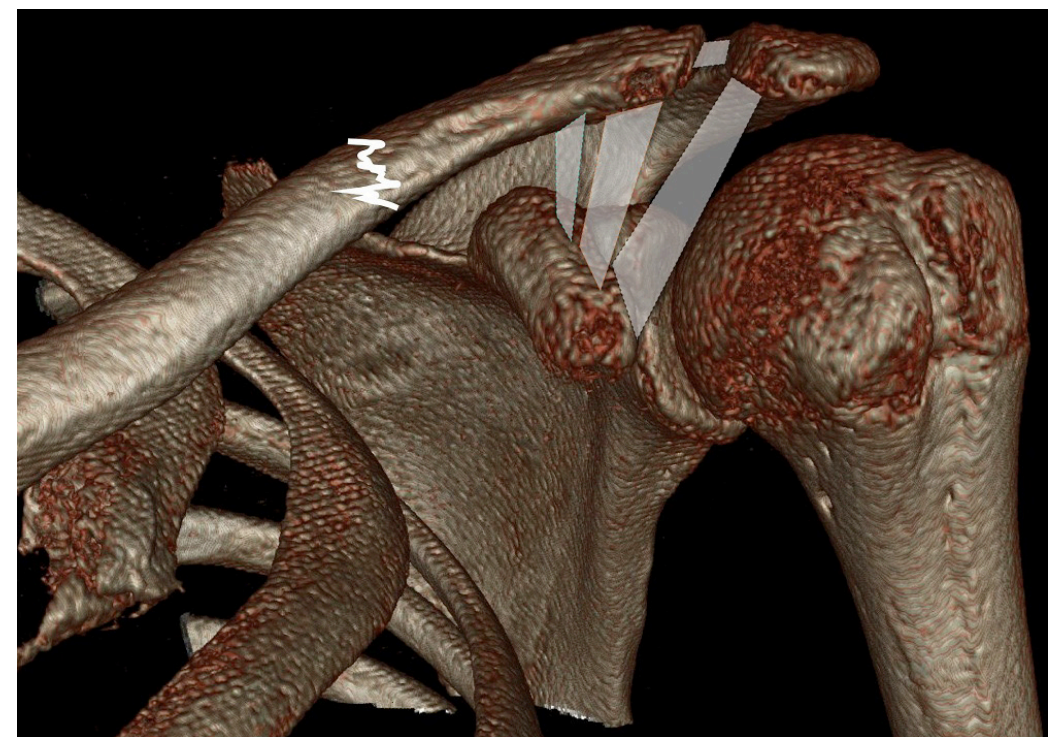

Figure 8: 3D CT model of Group 1 fracture involving middle third of clavicle (solid line)

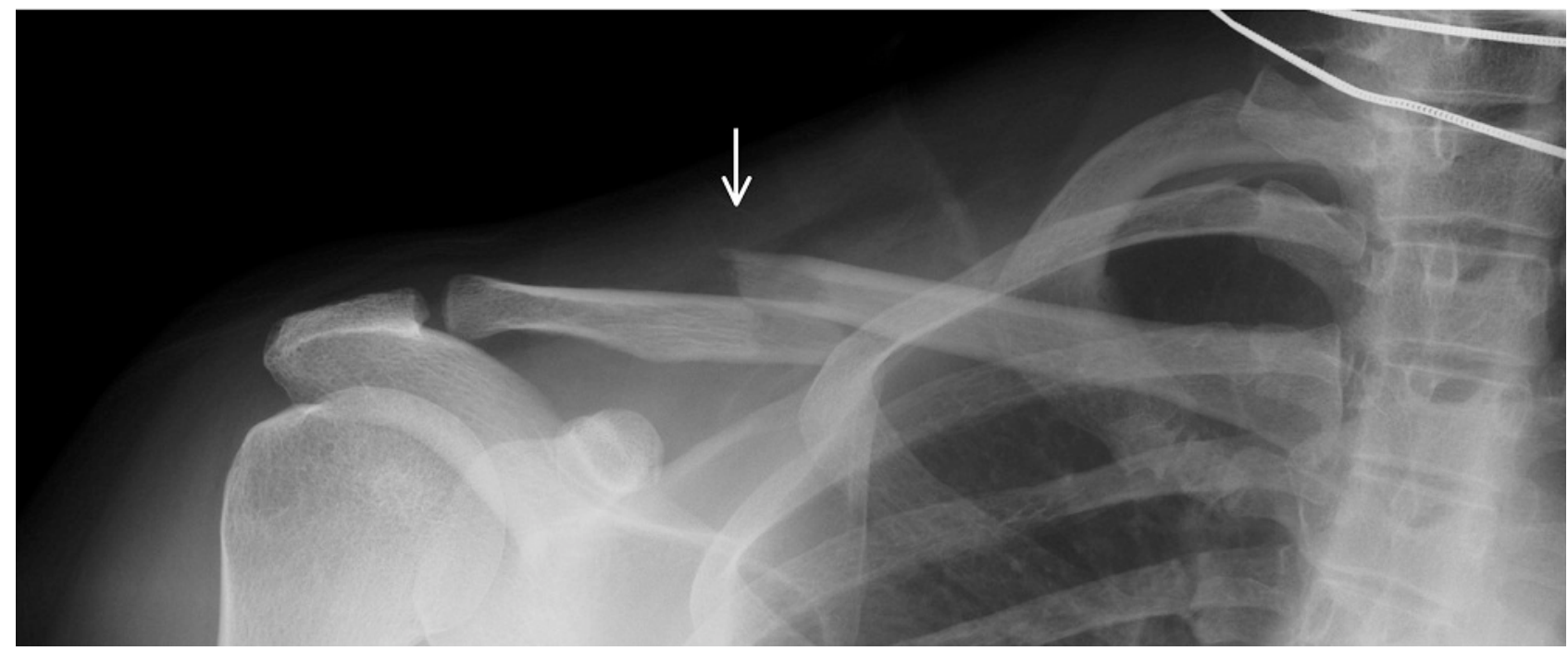

Figure 9: Radiograph demonstrates Group 1 fracture with mild inferior displacement of the lateral fragment (arrow)

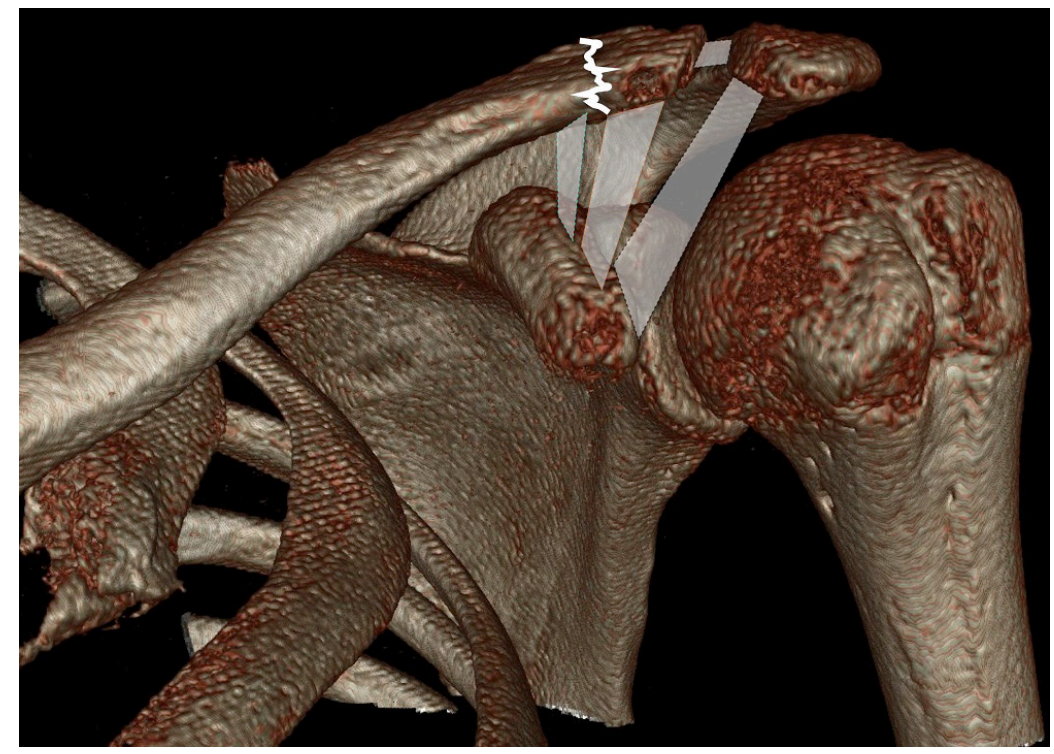

Figure 10: Type 1 occurring lateral to coroacoclaviclular ligament attachment with minimal displacement 


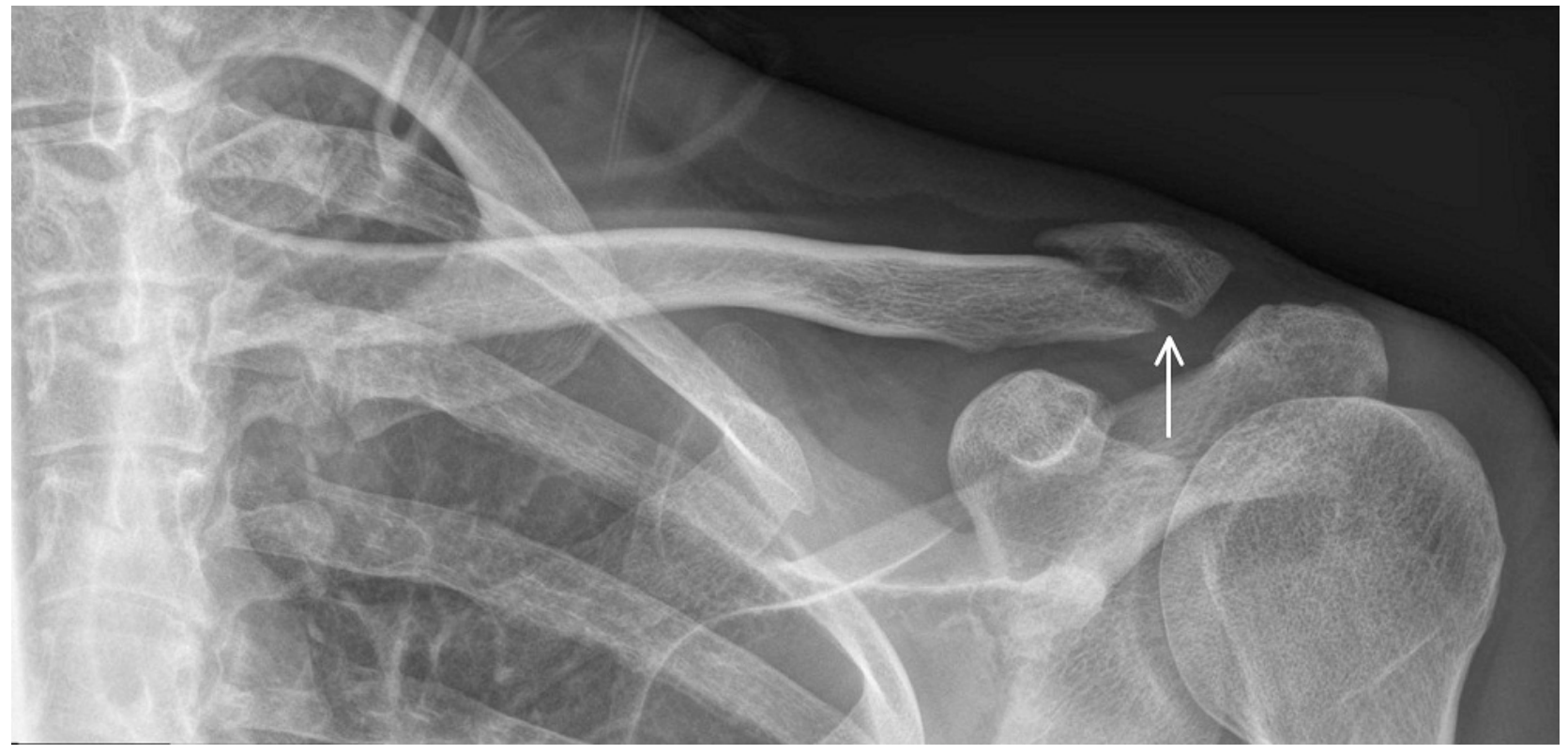

Figure 11: Type 1, fracture line without significant displacement

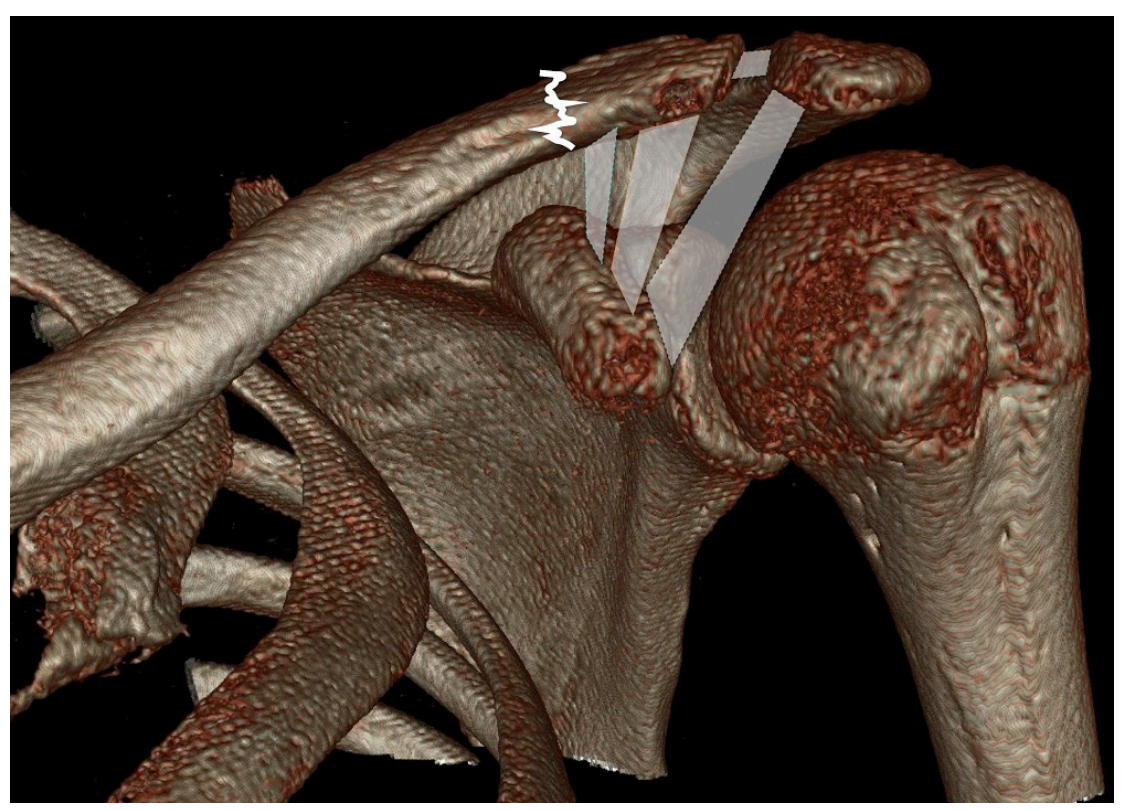

Figure 12: Type 2A, occurring medial to coracoclavicular ligament with ligaments attached to distal fragment

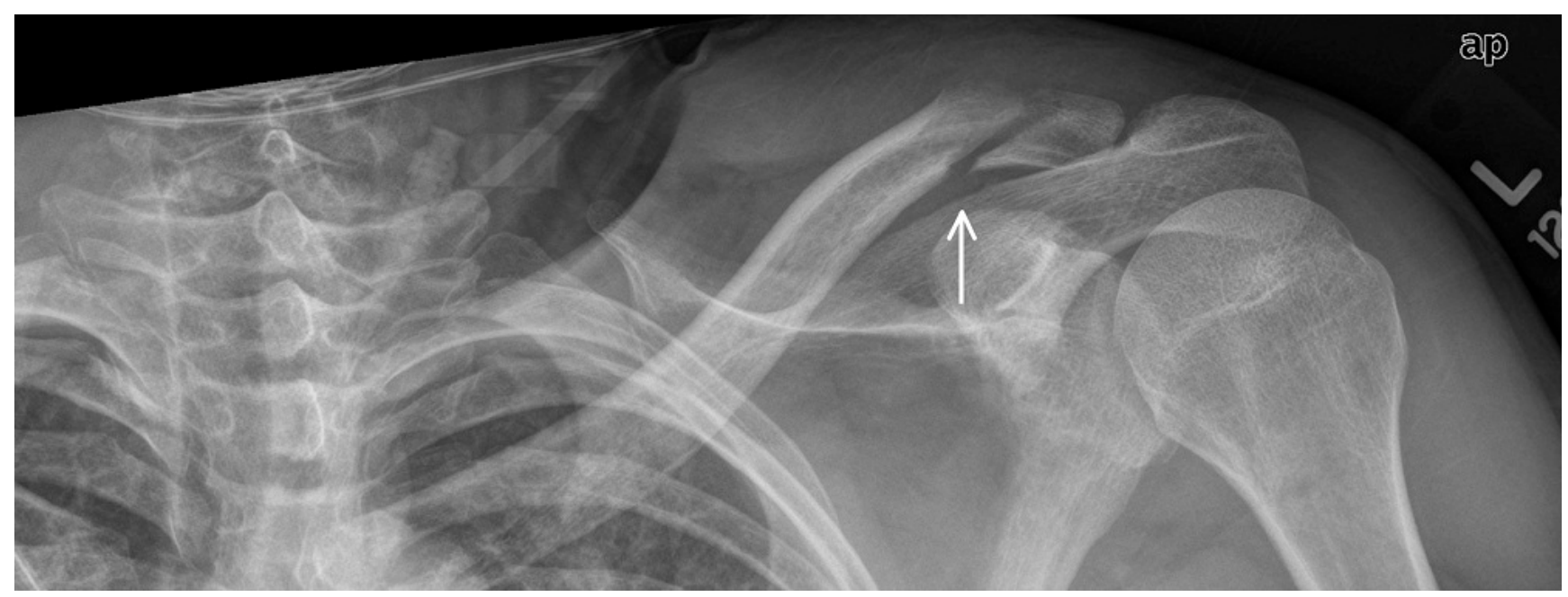

Figure 13: Type 2A, fracture occurring medial to conoid tubercle 


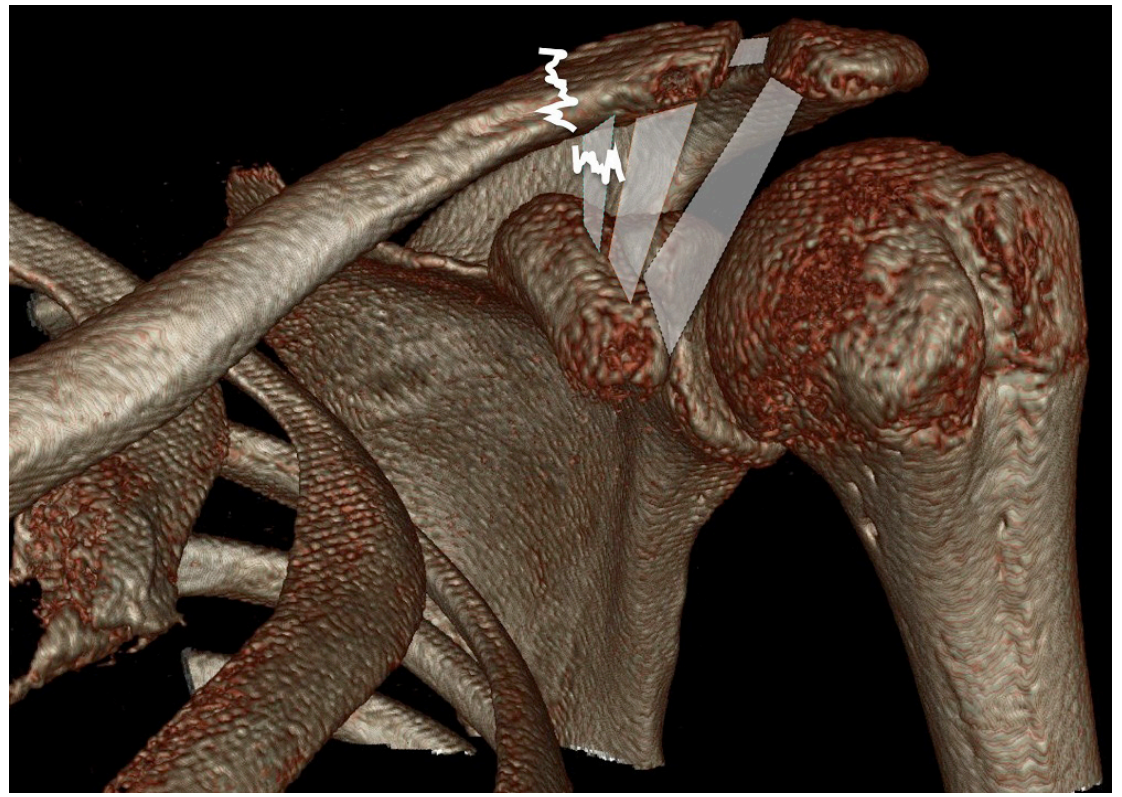

Figure 14: Type 2B, occurring medial to coracoclavicular ligament with disrupted conoid detached from proximal fragment, and trapezoid remaining attached to distal fragment

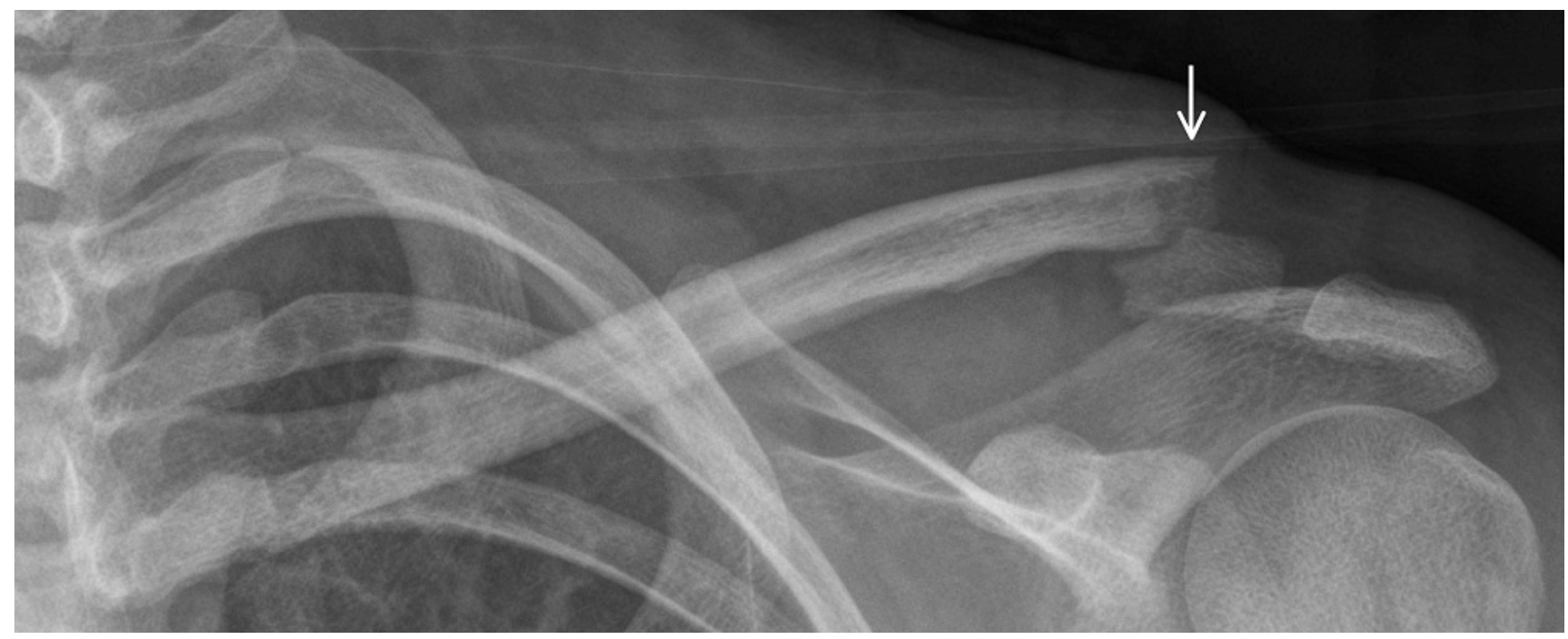

Figure 15: Type 2B, fracture distal to conoid tubercle with superior displacement medial fragment

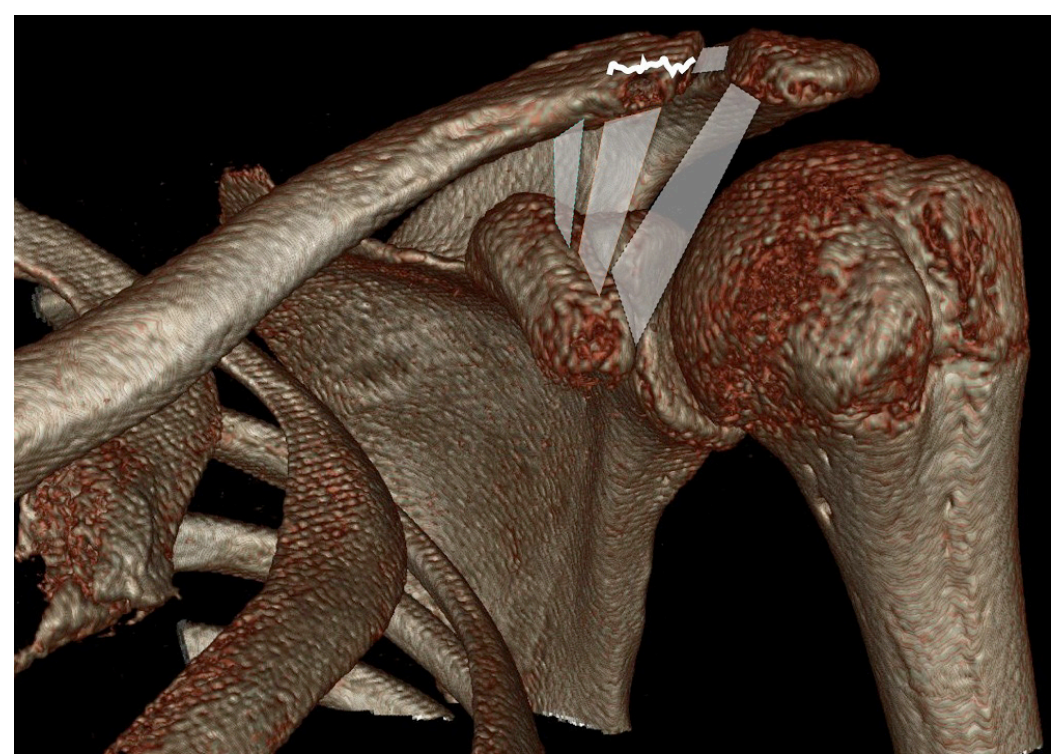

Figure 16: Type 3, with intra-articular extension 


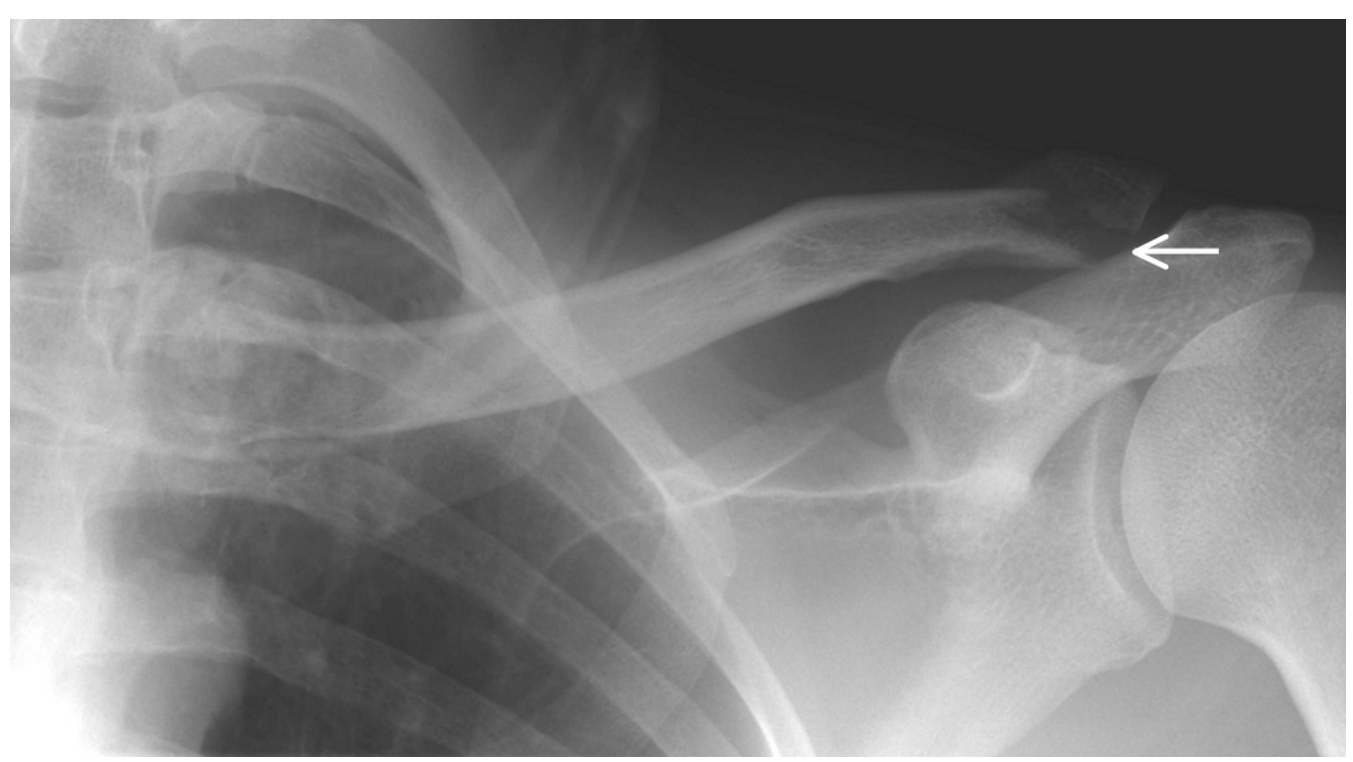

Figure 17: Type 3, fracture with intra-articular extension

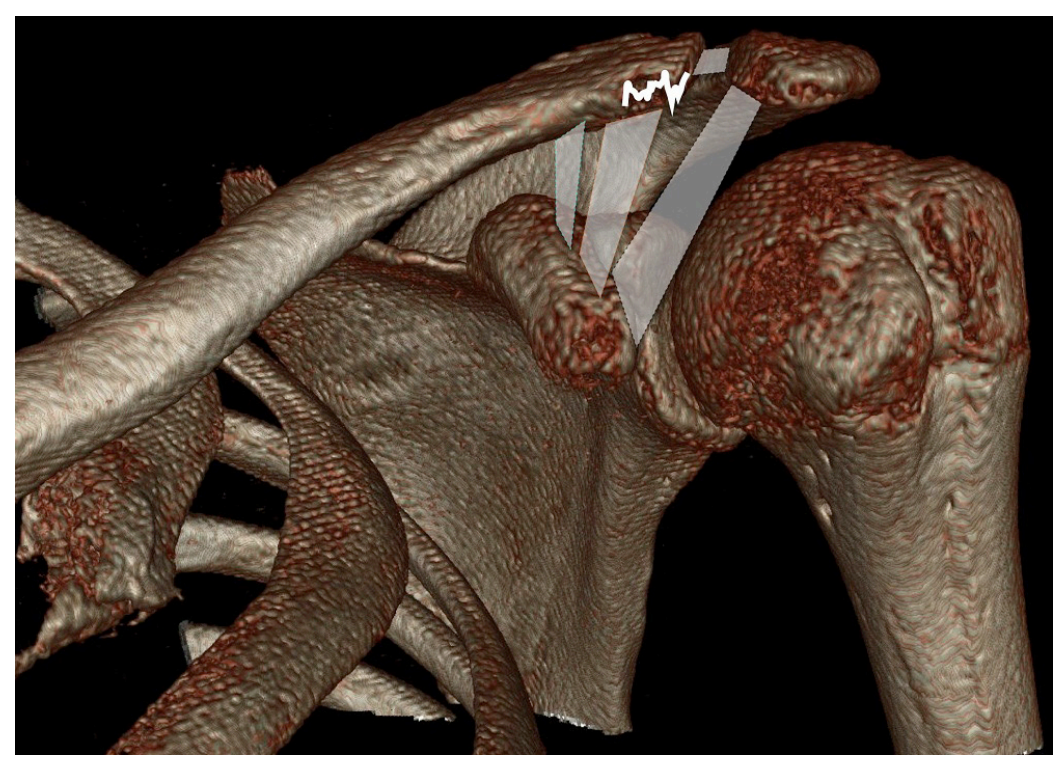

Figure 18: Type 4, a periosteal sleeve avulsion with medial fragment displaced superiorly

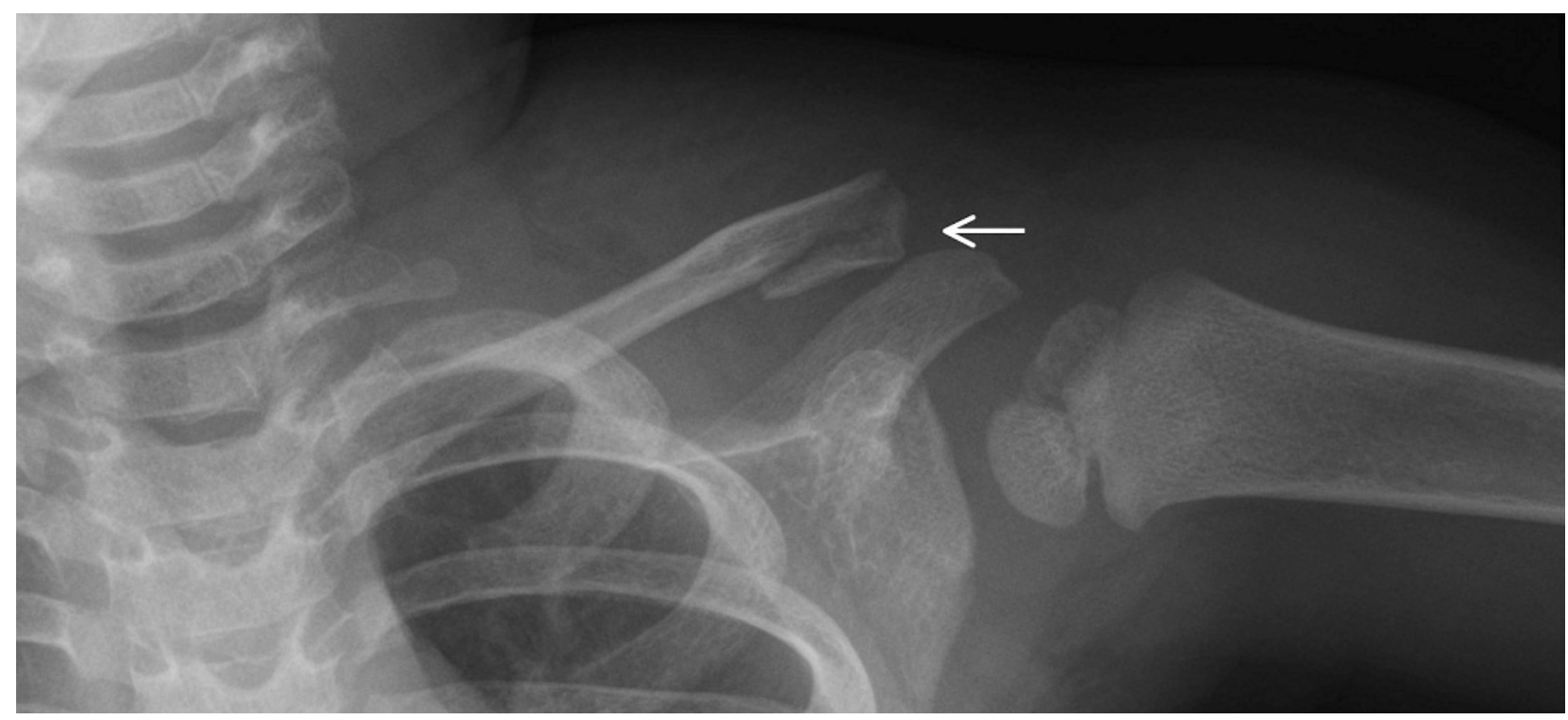

Figure 19: Type 4, periosteal sleeve avulsion 


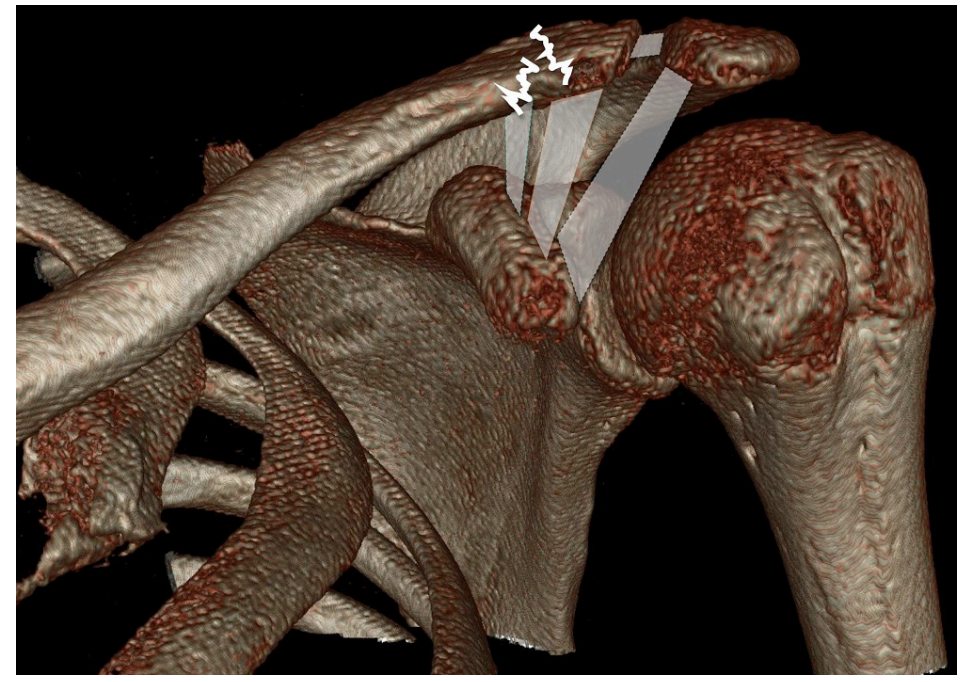

Figure 20: Type 5, avulsion of the coracoclavicular ligament

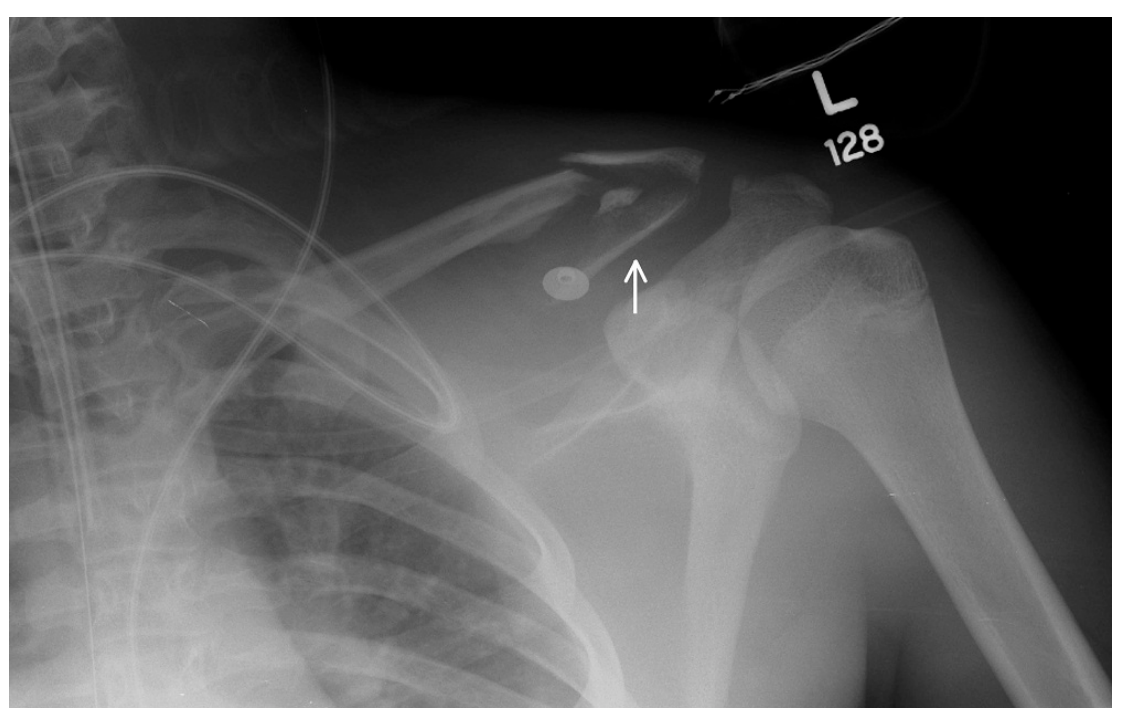

Figure 21: Comminuted avulsion of coracoclavicular ligament

Group 3 fractures involve the proximal clavicle and are the rarest variety. These have potential to damage mediastinal vascular structures when there is posterior displacement and sternoclavicular dislocation (Figure 22 and 23) [2].

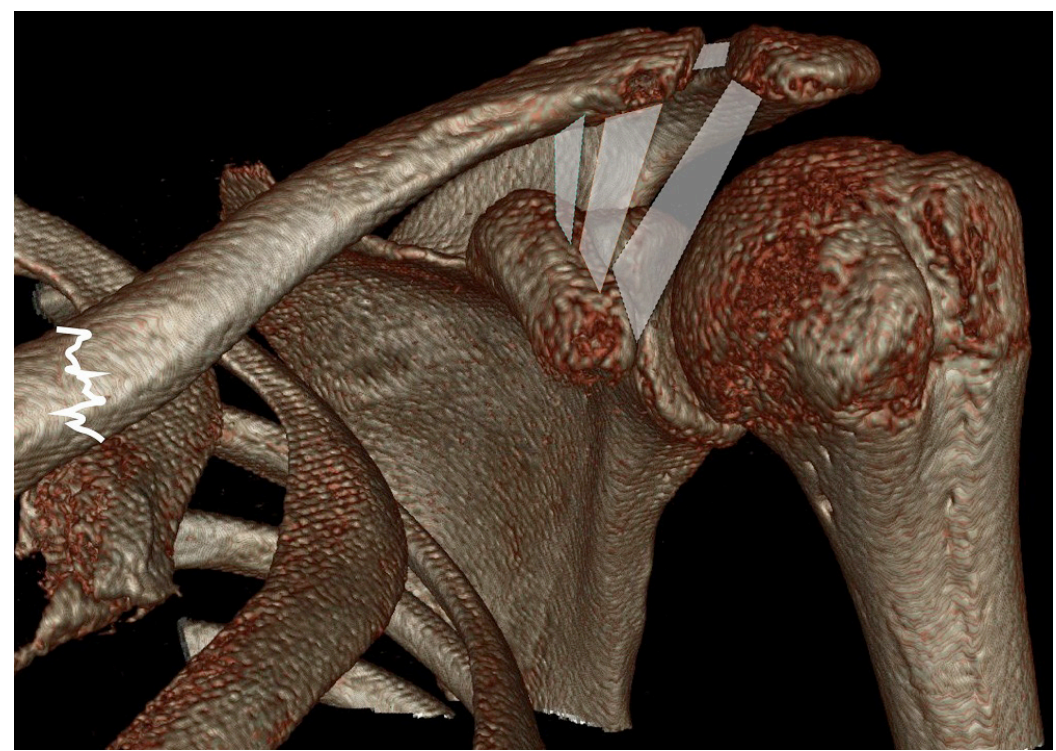

Figure 22: 3D CT model of Group 3 fracture involving medial third of clavicle. Model demonstrates conoid ligament, trapezoid ligament, coracoacromial ligament and acromioclavicular ligament. Fracture line noted with solid line 


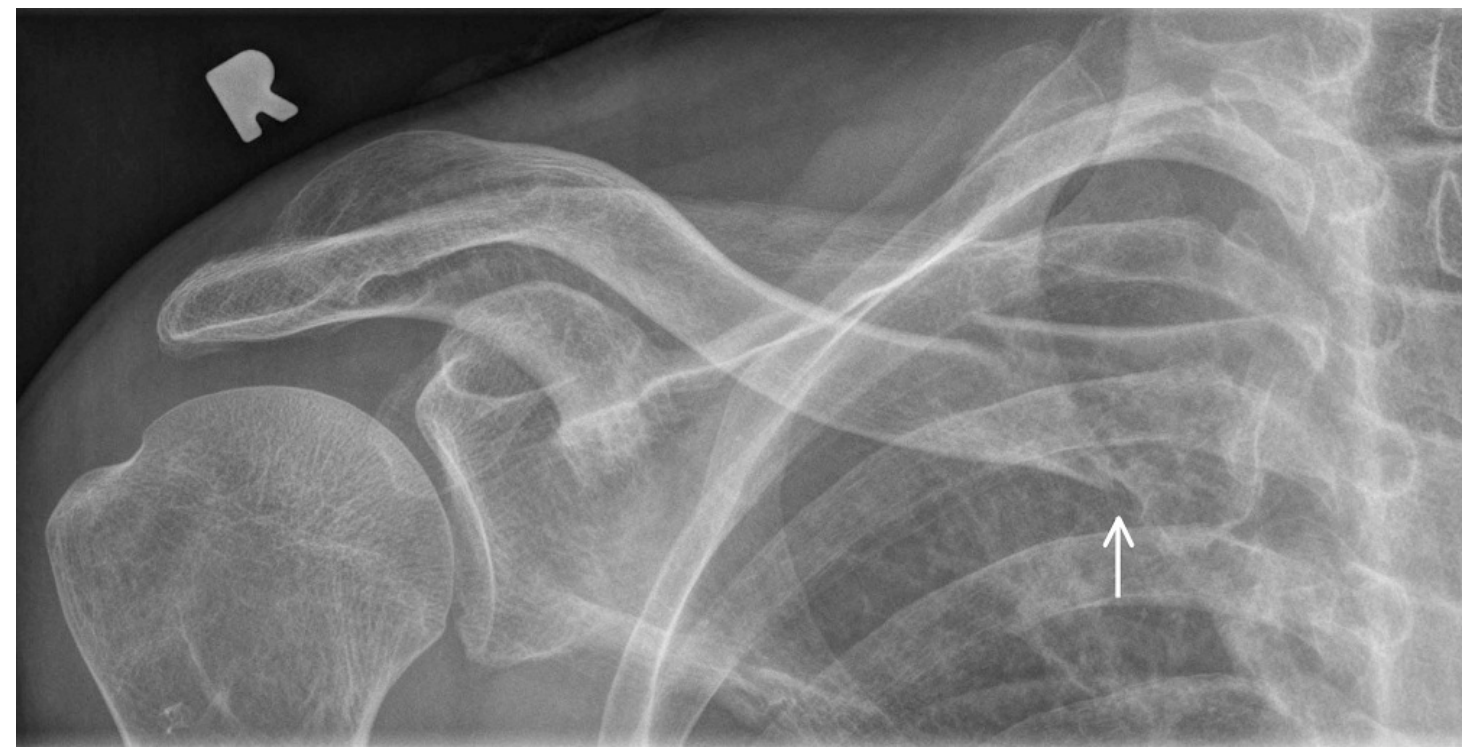

Figure 23: Radiograph demonstrates Group 3 fracture (arrow)

\section{Management}

Clavicle fractures are typically treated conservatively, although surgery is indicated if there is over $2 \mathrm{~cm}$ foreshortening, if fractures are open, if severe cosmetic deformity results, if there is neurovascular compromise, if concurrent unstable scapular fractures or if there is fragment displacement more than clavicle width [2]. Surgery is also usually employed if there is a $z$-shaped configuration to a comminuted fracture, with a fracture fragment oriented horizontally between the two larger clavicle fragments [11]. Classification influences treatment strategy if these criteria are not met. Group 1 and 3 fractures are usually managed nonoperatively, whereas Group 2 fractures more often require open reduction and fixation [2]. Conservative treatment includes a sling of figure-of- 8 brace for comfort applied for roughly 2-6 weeks, with early movement and rehabilitation encouraged if necessary. Potential techniques for open reduction include plate or wire fixation, intramedullary pins or interosseous sutures [1].

Group 1 fractures historically were treated conservatively. Many investigators advocate fixation of markedly comminuted or displaced group 1 fractures for early symptomatic benefit, however, since meta-analyses have demonstrated instances of nonunion and symptomatic malunion with non-operative management [2]. Surgical fixation is often employed for younger, active patients with greater than 1.5 to $2.0 \mathrm{~cm}$ clavicle foreshortening that may compromise functionality [1].

Group 2 fracture management varies according to the subtype, and factors influencing management include ligamentous integrity and comminution or displacement degree. Fractures tend to be stable, without necessitating operative management, if the trapezoid and conoid ligaments are intact and attached to the lateral and medial fragments (as in type 1), if the fracture is longitudinal in configuration (type 3), or if there is a periosteal sleeve avulsions (type 4). These fractures maintain opposed fragments and therefore can be conservatively managed without impairing function. Type 2A, $2 \mathrm{~B}$ and 5 fractures often result in poor fragment opposition and inferiorly displaced lateral fragments. There is thus a higher incidence of functional deficit and nonunion and surgical fixation is often indicated for these injuries [2].

Group 3 fractures respond well to conservative treatment since most are nondisplaced. Slings or figure-of- 8 braces are typically used for comfort, and the immobilization period lasts from 2-6 weeks [1]. Posterior fragment displacement and sternoclavicular dislocation can damage mediastinal vascular structures, and surgical reduction is often indicated for these cases. Fractures that compromise soft tissues, because poor functional status or delay fragment union may also be treated operatively [2].

\section{Conclusion}

Clavicle fractures are common injuries and may result in significant functional deficits if left untreated. Management decision depends on the degree of foreshortening, the amount of fracture displacement, cosmetic disfigurement and the fracture location. The Allman and Neer classification systems categorize fractures according to fracture site and guide management.

\section{References}

1. van der Meijden OA, Gaskill TR, Millett PJ (2011) Treatment of clavicle fractures: Current concepts Review. J Shoulder Elbow Surg 21: 423-9.

2. Sheehan SE, Gaviola G, Sacks A, Gordon R, Shi LL, et al. (2013) Traumatic Shoulder Injuries: A Force Mechanism Analysis of Complex Injuries to the Shoulder Girdle and Proximal Humerus. AJR Am J Roentgenol. 201: W409-24.

3. Robinson CM, Jenkins PJ, Markham PE, Begs I (2008) Disorders of the sternoclavicular joint. J Bone Joint Surg Br 90: 685-96.

4. Tubbs RS, Shah NA, Sullivan BP, Marchase ND, Cömert A, et al. (2009) The costoclavicular ligament revisited: a functional and anatomical study. Rom J Morphol Embryol 50: 475-9. 
5. Netter FH (2006) Atlas of Human Anatomy (4 $4^{\text {th }}$ Edn), Elsevier, Philadelphia, United States.

6. Moore KL, Dalley AF, Agur AM (2010) Clinically Oriented Anatomy (6 ${ }^{\text {th }}$ Edn), Lippincott Williams \& Wilkins, Baltimore, United States.

7. Owens BD, Gross TP (2006) The Floating Shoulder. Bone Joint J 88: 1419-24.

8. Sandstrom CK, Kennedy SA, Gross JA (2015) Acute Shoulder Trauma: What the Surgeon Wants to Know. Radiographics 35: 475-92.

9. O’Neill BJ, Hirpara KM, O’Briain D, McGarr C, Kaar TK (2011) Clavicle Fractures: a comparison of five classification systems and their relationship to treatment outcomes. Int Orthop 35: 909-14.

10. Sambandam B, Gupta R, Kumar S, Maini L (2014) Fracture of distal end clavicle: a review. J Clin Orthop Trauma 5: 65-73.

11. Hosalkar HS, Parikh G, Bomar JD, Bittersohl B (2012) Open Reduction and internal fixation of displaced clavicle fractures in adolescents. Orthop Rev 4: 10.4081/or.2012.e1.

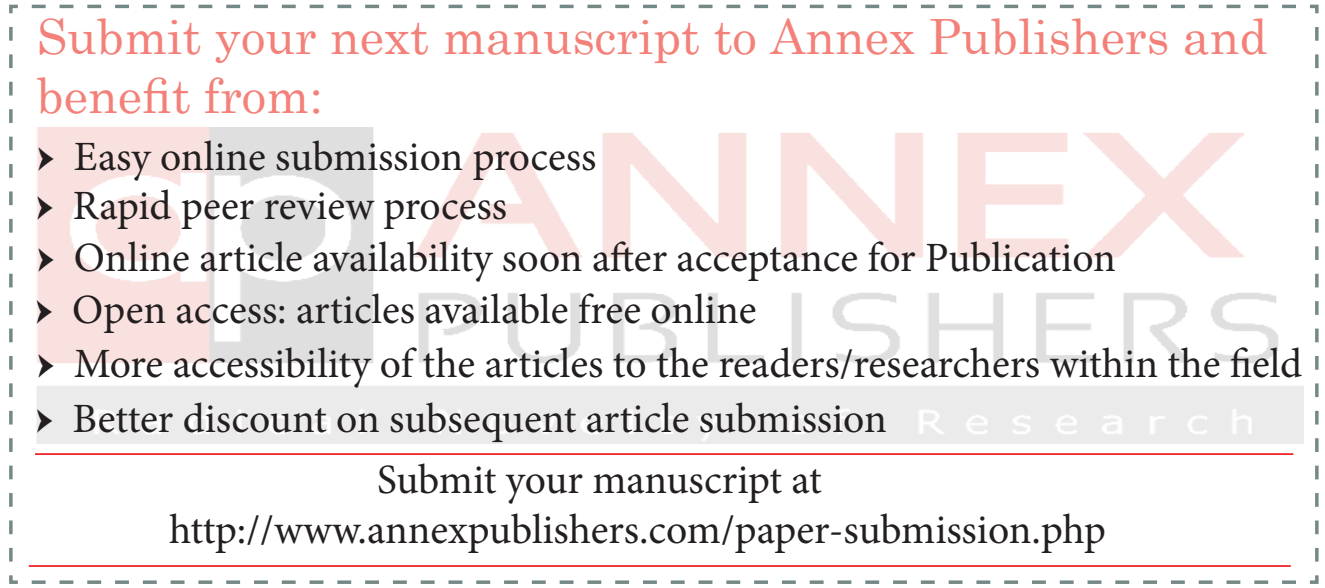

